Research Article

\title{
Simulation of Delamination Evolution of Slab Ballastless Track under Vertical Impact
}

\author{
Yu Liu $\mathbb{D}^{1,2}$ Qianqi Xu ${ }^{1},{ }^{1}$ Xiaodan Sun $\left(D,{ }^{1}\right.$ Guotao Yang ${ }^{(D)},{ }^{3}$ and Guotang Zhao ${ }^{3}{ }^{3}$ \\ ${ }^{1}$ School of Civil Engineering, Southwest Jiaotong University, Chengdu 610031, China \\ ${ }^{2}$ Key Laboratory of High-Speed Railway Engineering, Ministry of Education, Southwest Jiaotong University, \\ Chengdu 610031, China \\ ${ }^{3}$ Department of Science, Technology and Information Technology, China Railway, Beijing 100844, China
}

Correspondence should be addressed to Yu Liu; liuyu@swjtu.edu.cn

Received 2 May 2021; Accepted 9 June 2021; Published 29 June 2021

Academic Editor: Feng Fu

Copyright (C) 2021 Yu Liu et al. This is an open access article distributed under the Creative Commons Attribution License, which permits unrestricted use, distribution, and reproduction in any medium, provided the original work is properly cited.

\begin{abstract}
During the running of a high-speed train, the wheel may bounce on the rail due to the track irregularity. The wheel bounce could generate a vertical impact, leading to the initiation and expansion of delamination between layers of the track structure. In this paper, the evolution of the interfacial damage and delamination subjected to the vertical impact is simulated using finite element analysis (FEA). In the FEA, a bilinear cohesive zone model (CZM) is adopted to simulate the interface between the track slab and the CA mortar layer. For different levels of impact energy, the contact force, vertical deformation, absorbed energy, area of interfacial damage, and area of delamination are calculated and compared. The effects of the tangential and normal stiffness of the interface on the distribution of interfacial damage and delamination are investigated. The results show that the contact force, vertical deformation, absorbed energy, area of interfacial damage, and area of delamination increase with the increase of the impact energy. The area of interfacial damage in the compression stage is closely related to the tangential stiffness, whereas the area of delamination depends on the normal stiffness. The normal stiffness that gives the largest area of delamination is recommended to be taken as the lower bound of the normal stiffness for both controlling the delamination and preventing an exceedance of the track irregularity limit.
\end{abstract}

\section{Introduction}

The slab ballastless track structure of China Railway Track System type II (CRTS II SBTS) is a longitudinal continuous layered structure that consists of the track slab, the cement asphalt (CA) mortar layer, and the concrete base, as illustrated in Figure 1. It is specially used for high-speed railway (HSR) because it can provide high rail smoothness and ensure high comfort, stability, and safety of high-speed train. CRTS II SBTS is widely used in northern and eastern China. It was firstly applied in the Beijing-Tianjin HSR in 2008 and then utilized in the Beijing-Shanghai HSR in 2011. Up to now, the total mileage of CRTS II SBT application is over $9,000 \mathrm{~km}$, about $26 \%$ of the total mileage of China HSR.

Delamination of CRTS II SBTS refers to the phenomenon that the track slab separates from the CA mortar layer or the CA mortar layer separates from the concrete base. It can cause the buckling of CRTS II SBTS at the joint of two track slabs and endanger the operation safety of high-speed train $[1,2]$. A large amount of delamination has been found in the Beijing-Shanghai HSR, many of which exceed the height limit of $15 \mathrm{~mm}$ required by the "Maintenance Rules for Ballastless Track of High Speed Railway" in China [3]. For instance, Figure 2 shows one delamination observed in the Beijing-Shanghai HSR in 2018, approximately $2000 \mathrm{~mm}$ long, $560 \mathrm{~mm}$ wide, and $2 \mathrm{~mm}$ high. Delamination may occur in different stages of the construction and operation of CRTS II SBTS. In the construction stage, delamination may occur between the track slab and the CA mortar layer when the temperature difference between the top and bottom surface of the track slab is larger than $20^{\circ} \mathrm{C}$ and will grow under the combined action of the overall temperature rise of the top surface of track slab and the vertical temperature difference within the track structure [4-6]. In the operation 


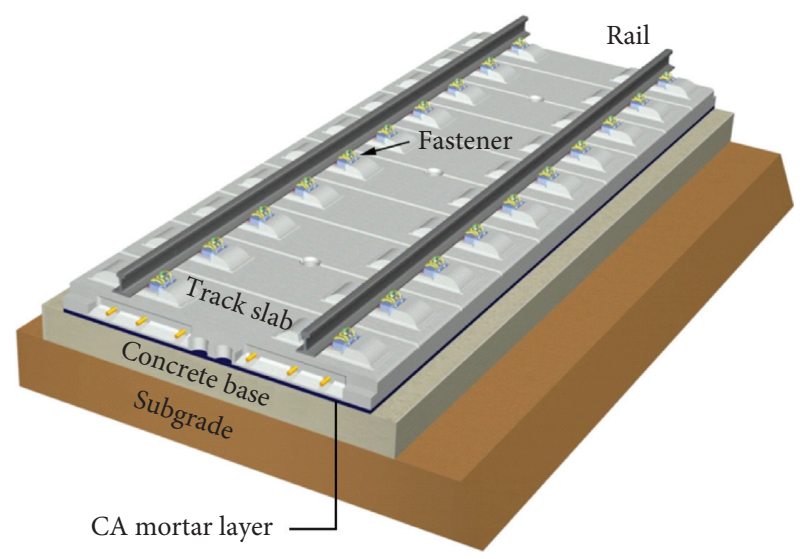

FIGURE 1: Sketch of CRTS II SBTS.

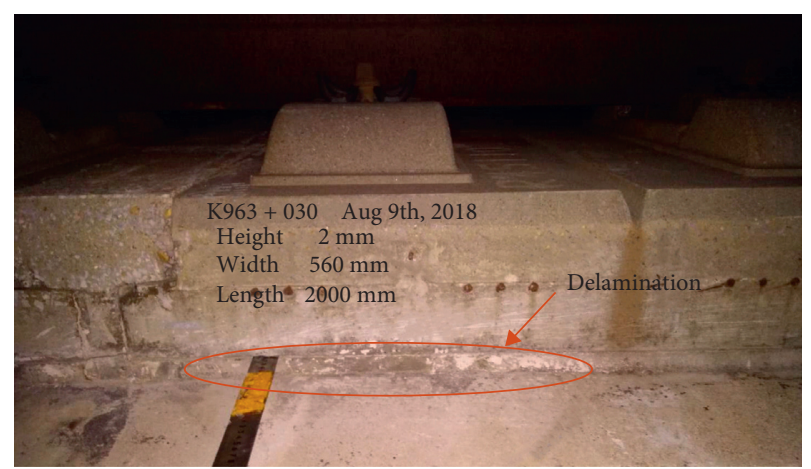

Figure 2: Example of delamination of CRTS II SBTS from the onsite survey of the Beijing-Shanghai HSR.

stage with trains running on the rail, delamination may expand rapidly under the additional impact load from train passage $[6,7]$.

During the running of a high-speed train, the wheel may roll, slide, or bounce on the rail. The bounce of the wheel happens when the wheel passes the top of an irregularity region at a high speed, as illustrated in Figure 3. At the moment when the wheel falls on the rail, the wheel will generate a vertical impact force on the rail which is instantly transmitted into the substructure via the track. This impact load is very different from the load in terms of track irregularity spectrum that is commonly used in the dynamic response analysis of the vehicle-track system [8, 9]. However, the track irregularity spectrum is rather correlated to the high-frequency vibration of the rail which has a limited effect on the substructure. The interfacial damage may be more closely correlated to the vertical impact on the track slab directly from the wheel bounce than to the track irregularity spectrum. There is very little research addressing the impact force caused by wheel bounce and even less on the response and damage of the track slab under the impact force. The impact-induced damage is more concerned in the field of aerospace composite materials [10-13] and explosion mechanics $[14,15]$. In the existing studies of the impactinduced damage, the damage is usually evaluated from the energy point of view, by studying the mutual transmission of potential and kinetic energy. Similarly, the impact energy caused by the wheel vertical impact consists of kinetic energy related to the falling speed and potential energy due to the height difference between the wheel and the track. Although the impact velocity of the wheel is much slower than that in the field of aerospace and explosion, it is still worth interpreting the input load from the energy point of view to investigate the generation and evolution of delamination. The wheel impact energy and the energy transmitted into the track slab, however, cannot be evaluated by the commonly used track irregularity spectrum.

On the other hand, CRTS II SBTS is a composite "sandwich" structure that contains steel bar, CA mortar, and concrete which is composed of aggregate, cement, and mineral powder. Therefore, the study of the delamination of CRTS II SBTS under the wheel impact is essentially a problem of the interfacial damage within composite material under vertical impact. In the field of railway track, there are very few studies addressing the damage from the vertical wheel impact and on determining a reasonable range of the impact energy for the wheel bounce. Kaewunruen et al. consider that the vertical loading from the wheel impact with a speed of $1.94 \mathrm{~m} / \mathrm{s}$ can be equivalent to that caused by a 600$\mathrm{kg}$-weight mass dropping from a height of $0.2 \mathrm{~m} \mathrm{[16].} \mathrm{Wu}$ et al. investigate the relationship between the damage of a concrete slab and the explosion load by changing the magnitude of explosion, the explosion location, and the thickness of the concrete slab [17]. Yilmaz et al. investigate the damage of a concrete slab caused by a hammer dropping from different heights [18]. They found that the greater the impact energy, the greater the maximum acceleration, maximum displacement, and area of interfacial damage. In the field of aerospace, the damage under impact is usually analyzed using a three-dimensional progressive damage analysis method that considers damage evolution and stiffness degradation [19-21]. In the method, the interface of composites is generally simulated using cohesive elements $[22,23]$, and the generation and development of the damage are described by the variation of the total stiffness of the cohesive elements. In this paper, the $3 \mathrm{D}$ progressive damage analysis method is adopted to simulate the damage evolution of CRTS II STBS. The interface of CRTS II STBS is simulated by cohesive elements with the parameters obtained from scale model push plate tests. The effects of the impact energy and interfacial bond property on the simulated interfacial damage and delamination are analyzed.

\section{Analysis Model of CRTS II SBTS under Vertical Impact}

The response of CRTS II SBTS under the vertical impact is simulated using ABAQUS. Considering that the delamination of CRTS II SBTS under the wheel impact is essentially the interfacial damage within composite material under the vertical impact, the finite element model includes three parts: a layered model of CRTS II SBTS, a cohesive zone model (CZM) that simulates the interface, and a puncher that carries all the impact energy from the vehicle. The impact energy applied on the layered model is estimated 


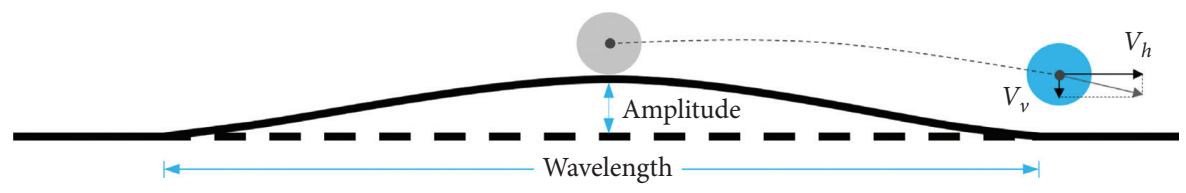

FIGURE 3: Diagram for the wheel running through the irregularity region.

based on the mass, velocity, and initial height of the puncher. Figure 4 shows the puncher and the layered model of the CRTS II SBTS inserted with a layer of cohesive elements.

2.1. Layered Model of CRTS II SBTS and Puncher. The geometrical and mechanic parameters of the layered model of CRTS II SBTS are listed in Table 1 according to [6]. The length, width, and thickness of the layered model are set to be the same as a real unit track slab. A layer of cohesive elements with a thickness of $10^{-3} \mathrm{~m}$ is set between the CA mortar layer and the track slab since the delamination is most likely to occur on the upper surface of the CA mortar layer [8]. The track slab, CA mortar layer, and concrete base are built using solid elements. For all nodes at the bottom and longitudinal boundary of the layered model, the constraint is applied to all six degrees of freedom. The contact between the puncher and the track slab as well as the contact between the track slab and the CA mortar is set to be hard contact in the normal direction and friction in the tangential direction with the penalty friction coefficient of 0.3 . The other contacts are set to be tie.

As illustrated in Figure 3, the ratio of the vertical velocity to the horizontal velocity can be assumed to be equal to the ratio of the amplitude to the half of the wavelength of the irregularity. Therefore, the impact energy that the puncher carries includes two parts: the potential energy related to the amplitude of the irregularity and the kinetic energy related to the initial vertical velocity. For the train CRH380A, the weight on one wheel is $6400 \mathrm{~kg}$ including the weight of the car body, two bogies, and four wheelsets. According to the level I management value in "Maintenance Rules for Ballastless Track of High Speed Railway" [3], the amplitude of irregularity is taken to be $4 \mathrm{~mm}$ and the wavelength is $30 \mathrm{~m}$ [24]. With a speed of $300 \mathrm{~km} / \mathrm{h}$, the total energy of the wheel at the instant of bounce will be $257.5 \mathrm{~J}$. Therefore, the upper limit of the impact energy in the finite element analysis (FEA) is set to be $300 \mathrm{~J}$. Another six levels of impact energy, $20 \mathrm{~J}, 50 \mathrm{~J}, 100 \mathrm{~J}, 150 \mathrm{~J}, 200 \mathrm{~J}$, and $250 \mathrm{~J}$, are also considered in the FEA to evaluate the effect of the impact energy. The variation of the impact energy is achieved by changing the initial vertical velocity of the puncher which is a $1000-\mathrm{kg}$ weight ball with a diameter of $0.1 \mathrm{~m}$ that drops from a fixed height.

2.2. Cohesive Zone Model (CZM). A bilinear CZM is employed to characterize the force-displacement relationship during the process from interfacial damage initiation to delamination, as shown in Figure 5.

Assuming that $\sigma_{n}, \sigma_{t}$, and $\sigma_{s}$ are the interfacial stresses in normal and two tangential directions, respectively, $\sigma_{n}^{0}, \sigma_{t}^{0}$, and $\sigma_{s}^{0}$ are the corresponding interfacial strength. For a tangentially isotropic interface, $\sigma_{t}=\sigma_{s}$ and $\sigma_{t}^{0}=\sigma_{s}^{0}$. According to the bilinear CZM, the force-displacement curve increases linearly during loading, with the slope of the stiffness $E_{n}$ and $E_{s}$ for normal and tangential direction, respectively. When the force-displacement curve reaches the peak, the interfacial damage initiates, which can be quantitatively judged by the Quads criterion:

$$
\left(\frac{\sigma_{n}}{\sigma_{n}^{0}}\right)^{2}+\left(\frac{\sigma_{t}}{\sigma_{t}^{0}}\right)^{2}+\left(\frac{\sigma_{s}}{\sigma_{s}^{0}}\right)^{2} \geq 1,
$$

where $\sigma_{n}=\left(\sigma_{n}+\left|\sigma_{n}\right|\right) / 2$. The stress for the damage initiation is the interfacial strength, $\sigma_{n}^{0}$ and $\sigma_{s}^{0}$, for the normal and tangential direction, respectively, while the corresponding displacement is $\delta_{n}^{0}$ and $\delta_{s}^{0}$, respectively. Therefore, $E_{n}=\sigma_{n}^{0} / \delta_{n}^{0}$ and $E_{s}=\sigma_{s}^{0} / \delta_{s}^{0}$.

According to the bilinear CZM, the softening evolution after damage initiation is also linear. Thus the stress after damage occurs can be given by

$$
\left\{\begin{array}{l}
\sigma_{n}=(1-D) E_{n} \delta_{n}, \\
\sigma_{s}=(1-D) E_{s} \delta_{s},
\end{array}\right.
$$

where $\delta_{n}$ and $\delta_{s}$ are the displacements and $D$ represents the overall damage in the CZM, which is zero initially and then gradually evolves from 0 to 1 upon further loading:

$$
D=\frac{\delta_{m}^{f}\left(\delta_{m}-\delta_{m}^{0}\right)}{\delta_{m}\left(\delta_{m}^{f}-\delta_{m}^{0}\right)}
$$

where $m=n$ for the normal direction and $m=t$ or $m=s$ for the longitudinal or transverse tangential direction. When $D$ equals 1 , delamination occurs. Assuming $\delta_{n}^{f}, \delta_{s}^{f}$ are the normal and tangential displacement for the moment of delamination occurrence, respectively, the corresponding fracture toughness, $G_{\text {IC }}$ and $G_{\text {IIC }}$, can be measured by the triangle area in Figure $5, G_{\text {IC }}=1 / 2 \sigma_{n}^{0} \delta_{n}^{f}$ or $G_{\text {IIC }}=1 / 2 \sigma_{s}^{0} \delta_{s}^{f}$. The delamination initiation can be evaluated by fracture toughness. It can be judged that the delamination occurs if the fracture toughness follows the equation below:

$$
\left(\frac{G_{I}}{G_{\text {IC }}}\right)^{2}+\left(\frac{G_{\text {II }}}{G_{\text {IIC }}}\right)^{2}+\left(\frac{G_{\text {III }}}{G_{\text {IIIC }}}\right)^{2}=1 .
$$

The parameters of the CZM are determined by model tests in which normal cohesive parameters are determined from the vertical push plate test, and tangential cohesive parameters are determined from the horizontal push plate test. The specimen of the CRTS II SBTS has the length, width, and height of $60 \mathrm{~cm} \times 20 \mathrm{~cm} \times 20 \mathrm{~cm}$, bonded on the base via the CA mortar layer with the height of $3 \mathrm{~cm}$. The 


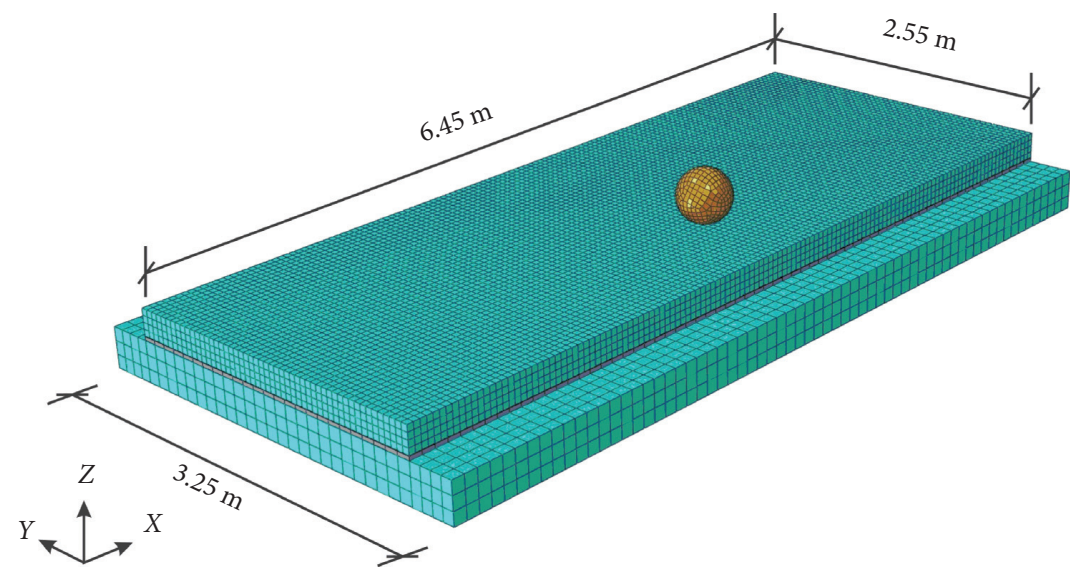

(a)

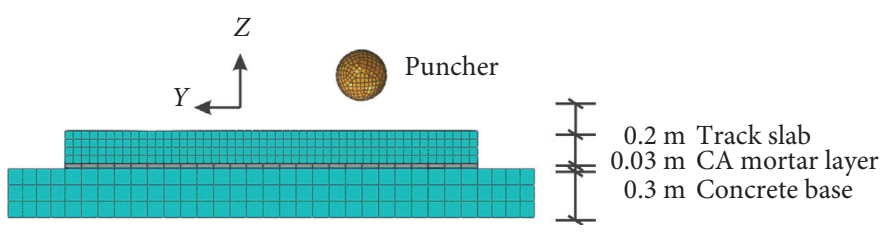

(b)

FIGURE 4: Dimension of the analysis model (a) and the thickness for each layer (b).

TABLE 1: Geometrical and mechanic parameters of the layered model of CRTS II SBTS.

\begin{tabular}{lccccc}
\hline Layers & Density $\left(\mathrm{kg} / \mathrm{m}^{3}\right)$ & $E(\mathrm{MPa})$ & Length $(\mathrm{m})$ & Width $(\mathrm{m})$ & Thickness $(\mathrm{m})$ \\
\hline Track slab & 2500 & 36000 & 6.45 & 2.55 & 0.2 \\
CA mortar layer & 1950 & 10000 & 6.45 & 2.55 & 0.03 \\
Concrete base & 2400 & 22000 & 6.45 & 3.25 & 0.3 \\
\hline
\end{tabular}

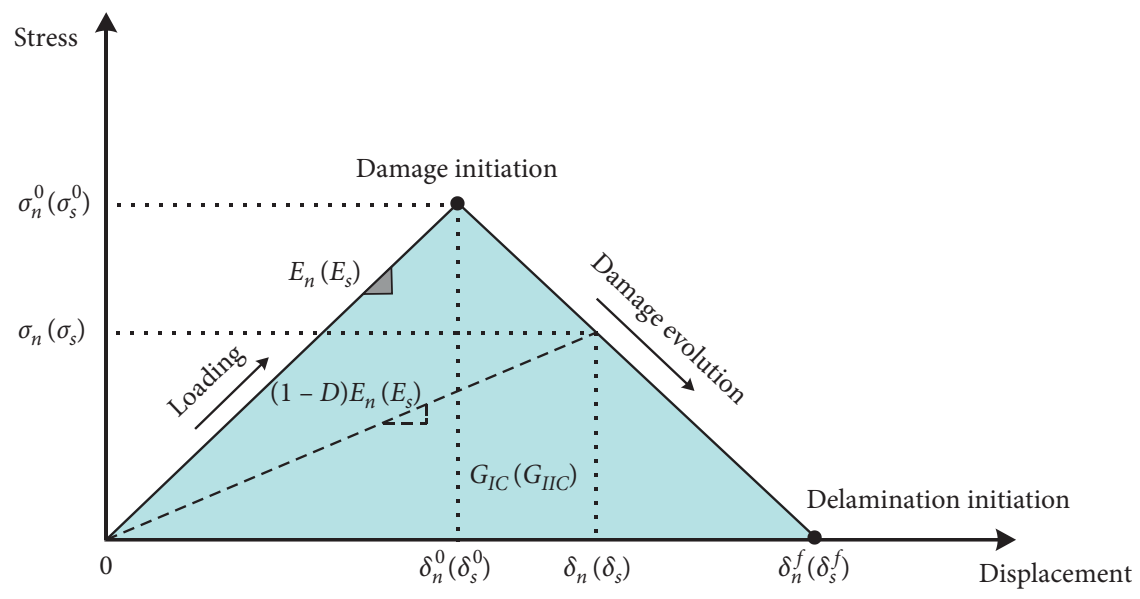

FIGURE 5: The bilinear stress-displacement relationship for the CZM.

mechanic parameters of the concrete for the track slab and base are the same as listed in Table 1 . The specimens were tested 28 days after the CA grouted. The setup of the vertical push plate test is shown in Figure 6. The track slab is lifted vertically with the load applied at the midpoint of the track slab. Two dial gauges are placed $20 \mathrm{~cm}$ away from the midpoint at each side. The setup of the horizontal push plate test is shown in Figure 7. In the test, the load is horizontally applied at the center of one end cross-section, and two dial gauges are arranged horizontally at both of the two ends of the specimen. The relative displacement between the track slab and the base was tested using a linear variable differential transformer (LVDT). The jacks work synchronously by an automation control system to provide a constant-rate 


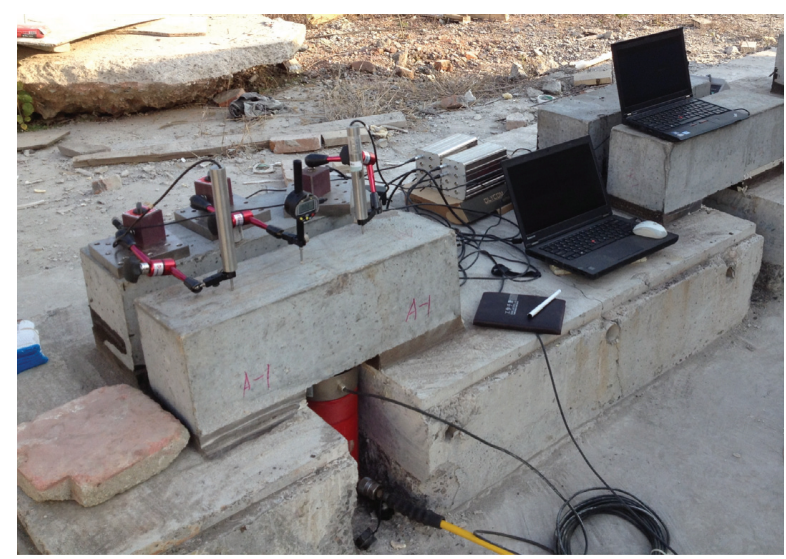

FIGURE 6: Setup of the scale central-loading vertical push plate test.

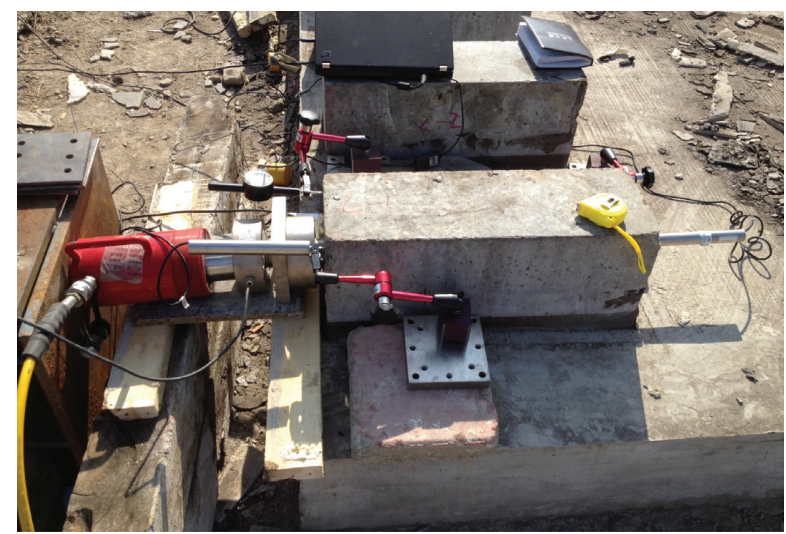

Figure 7: Setup of the scale horizontal push plate test.

increased load. The force-displacement curves obtained from the vertical and horizontal push plate test are plotted in Figures 8 and 9 , respectively. $\sigma_{n}^{0}$ and $\sigma_{s}^{0}$ can be determined by the peak stress of the vertical and horizontal force-displacement curve, respectively. $\delta_{n}^{0}$ and $\delta_{s}^{0}$ are then identified corresponding to $\sigma_{n}^{0}$ and $\sigma_{s}^{0}$, respectively. Afterward, $E_{n}$ and $E_{s}$ can be calculated using $E_{n}=\sigma_{n}^{0} / \delta_{n}^{0}$ and $E_{s}=\sigma_{s}^{0} / \delta_{s}^{0}$. $\delta_{n}^{f}$ and $\delta_{s}^{f}$ are visually picked as the displacement after which the fluctuation in the force-displacement curve is slight. Based on $\delta_{n}^{f}$ and $\delta_{s}^{f}, G_{\mathrm{IC}}$ and $G_{\mathrm{IIC}}$ can be calculated using $G_{\text {IC }}=1 / 2 \sigma_{n}^{0} \delta_{n}^{f}$ or $G_{\text {IIC }}=1 / 2 \sigma_{s}^{0} \delta_{s}^{f}$. The determined cohesive parameters are indicated in Figures 8 and 9 and listed in Table 2.

\section{Simulation Results}

3.1. Contact Force. The contact force for different impact energies is shown in Figure 10. For each curve in Figure 10, the ascending part represents the compression stage in which the puncher presses down the track slab, whereas the descending part describes the rebound stage in which the puncher begins to rebound. The contact force reaches the peak value at approximately $2 \times 10^{-3} \mathrm{~s}$ regardless of the impact energy. The maximum contact force versus the impact energy and the contact time versus the impact energy

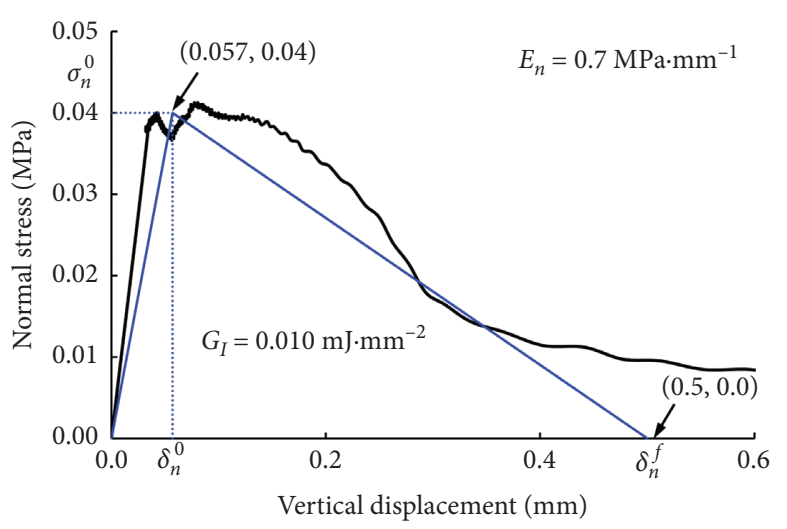

FIGURE 8: Force-displacement curve of the vertical push plate test.

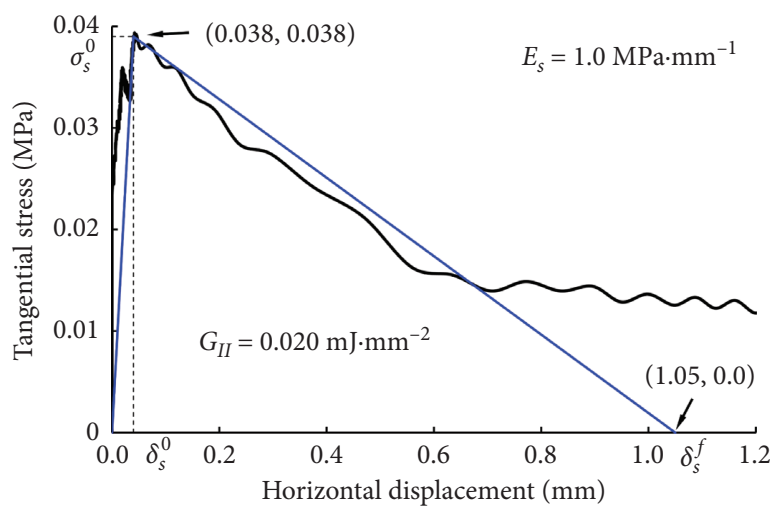

FIGURE 9: Force-displacement curve of the horizontal push plate test.

are shown in Figure 11. As seen from Figure 11, the maximum contact force varies linearly with the impact energy. The contact time for the impact energy of $20 \mathrm{~J}$ is slightly larger than that for other impact energies. After the impact energy exceeds $150 \mathrm{~J}$, the contact time is not sensitive to the level of the impact energy.

3.2. Vertical deformation of the Track Slab. As shown in Figure 4, one of the two long sides of the track slab, which is closer to the puncher, is chosen for the illustration of the vertical deformation. Figure 12 shows the vertical deformation of the selected side for the moment when the impact point achieves the maximum deformation in the compression stage. As seen from Figure 12, most of the slab shows a downward compression deformation. When the impact energy is larger than $50 \mathrm{~J}$, there will be an upward deformation at both sides of the track slab due to the constraint applied at the end of the track slab. The maximum vertical deformation at the impact point increases with the impact energy, from $0.2 \mathrm{~mm}$ for the impact energy of $20 \mathrm{~J}$ to $0.65 \mathrm{~mm}$ for the impact energy of $300 \mathrm{~J}$. Figure 13 shows the vertical deformation of the selected side of the track slab at the moment when the impact point achieves the maximum deformation in the rebound stage. As seen from Figure 13, most of the slab shows an upward tensile deformation. 
TABle 2: Parameters of the cohesive zone model.

\begin{tabular}{lccccc}
\hline Value & $\sigma^{0}(\mathrm{MPa})$ & $\delta^{0}(\mathrm{~mm})$ & $E\left(\mathrm{MPa} \cdot \mathrm{mm}^{-1}\right)$ & $G\left(\mathrm{~mJ} \cdot \mathrm{mm}^{-2}\right)$ & $\delta^{f}(\mathrm{~mm})$ \\
\hline Normal direction & 0.040 & 0.057 & 0.7 & 0.010 & 0.5 \\
Tangential direction & 0.038 & 0.038 & 1.0 & 0.020 & 1.05 \\
\hline
\end{tabular}

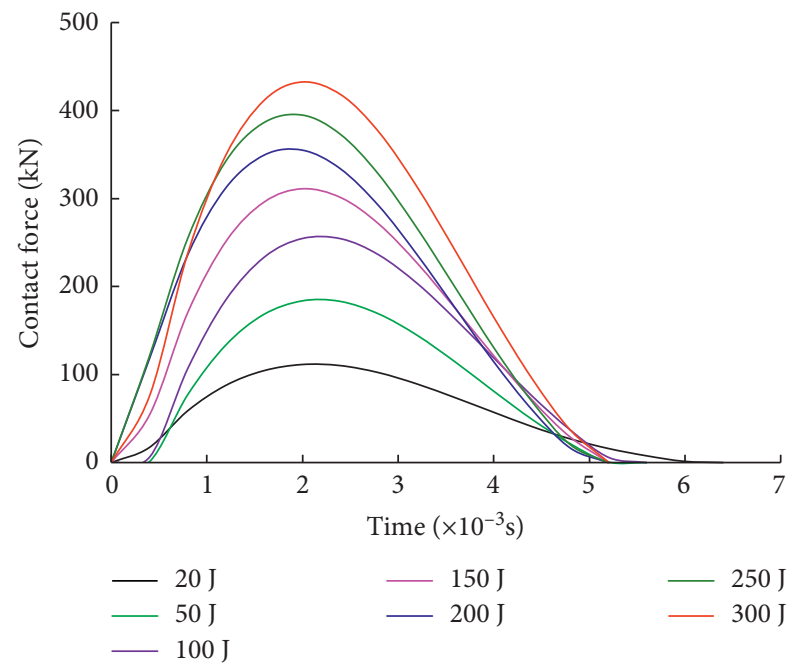

FIGURE 10: Time histories of the contact force for different impact energies.

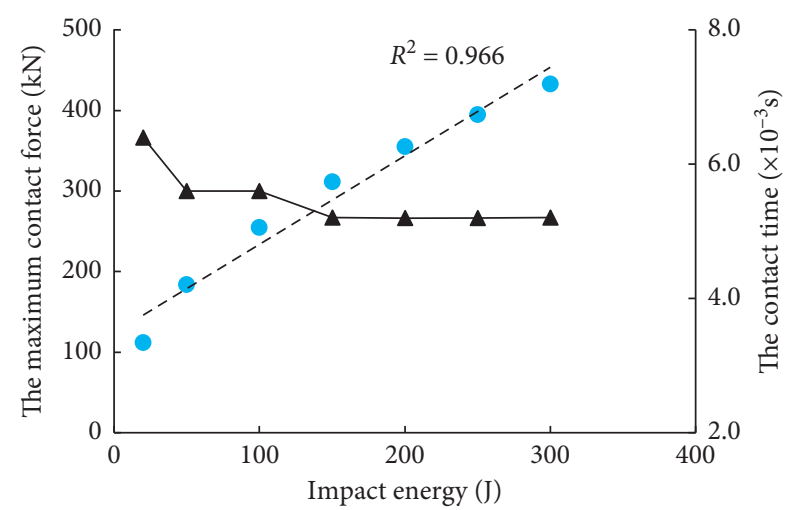

FIgURE 11: The maximum contact force (blue dot) and contact time (black triangle) vs. impact energy.

When the impact energy is lower than $100 \mathrm{~J}$, there will be a downward deformation at both sides of the track slab due to the constrain applied at the end of the track slab. The maximum vertical deformation at the impact point increases with the impact energy, from $0.1 \mathrm{~mm}$ for the impact energy of $20 \mathrm{~J}$ to $1.1 \mathrm{~mm}$ for the impact energy of $300 \mathrm{~J}$.

The ratio of the maximum rebound deformation (crest in Figure 13) and the maximum compression deformation (trough in Figure 12) for different impact energies are calculated, as shown in Figure 14. As seen from Figure 14, the ratio of the deformation increases as the impact energy increases. When the impact energy is less than approximately $130 \mathrm{~J}$, the maximum rebound deformation is smaller

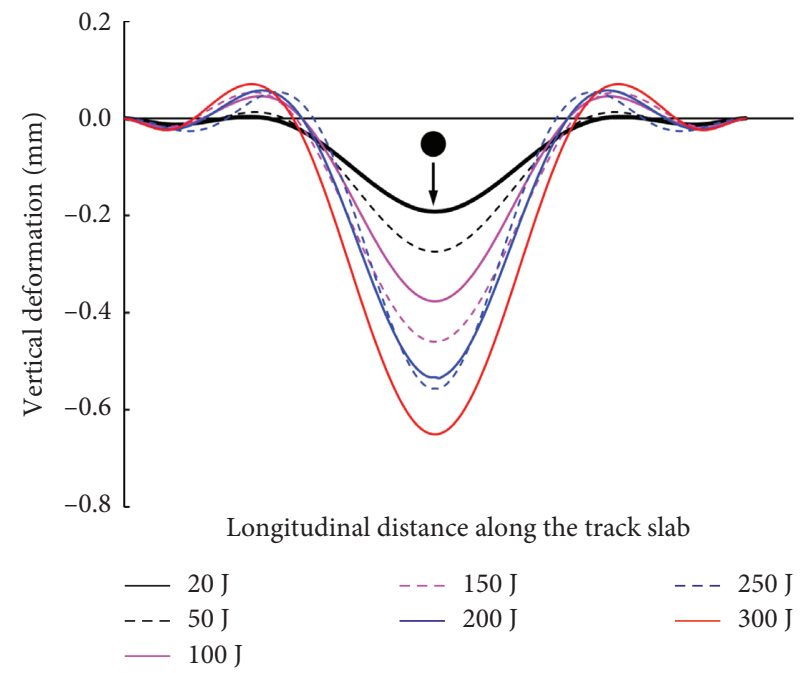

FIgURE 12: The maximum compression deformation for the selected side of the track slab for different impact energies.

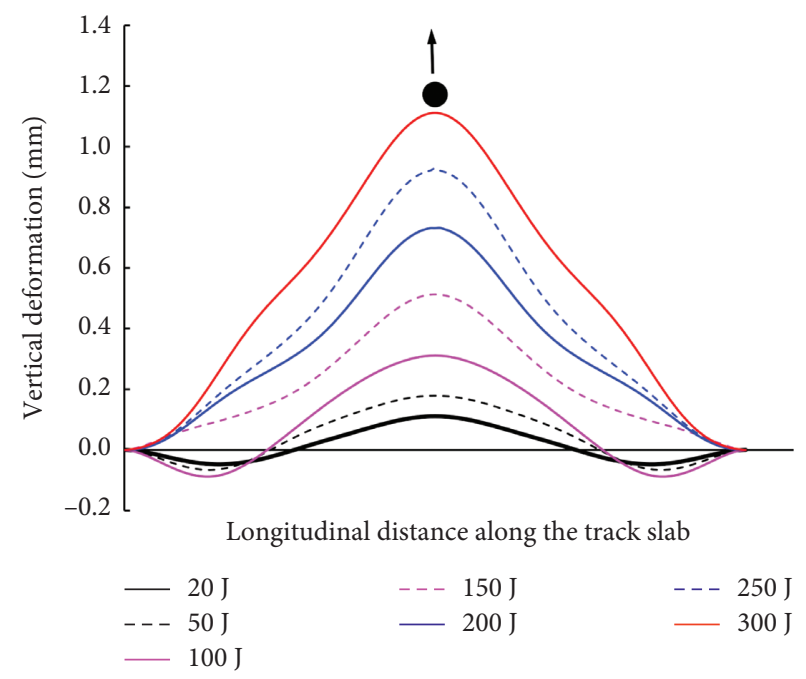

FIGURE 13: The maximum rebound deformation for the selected side of the track slab for different impact energies.

than the maximum compression deformation. For the impact energy of $300 \mathrm{~J}$, the maximum rebound deformation is almost 1.7 times the maximum compression deformation of $0.65 \mathrm{~mm}$. For the impact energy of $20 \mathrm{~J}$, the maximum rebound deformation is $0.11 \mathrm{~mm}$ which exceeds $\delta_{n}^{0}$ of $0.057 \mathrm{~mm}$ in Table 2. It indicates that the interfacial damage will initiate even if the impact energy is $20 \mathrm{~J}$. The maximum rebound deformation for the impact energy of $150 \mathrm{~J}$ is $0.51 \mathrm{~mm}$, which exceeds $\delta_{n}^{f}$ of $0.5 \mathrm{~mm}$ in Table 2. This 


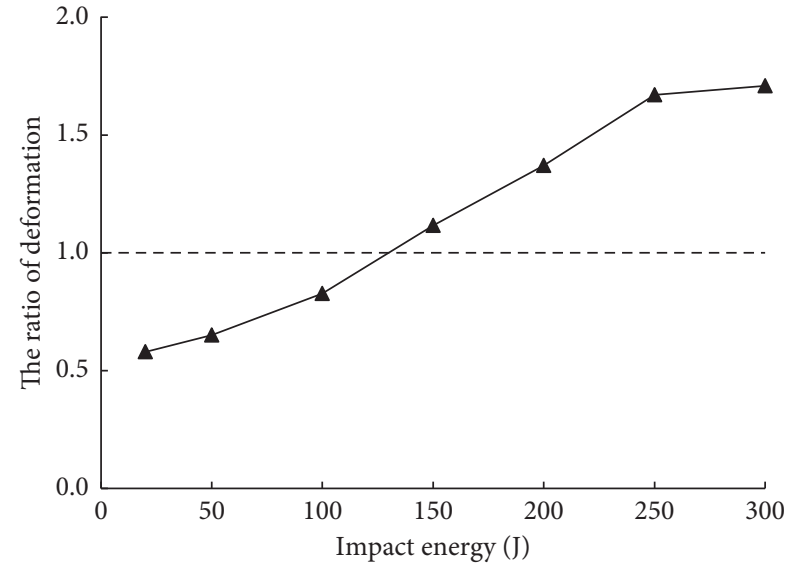

Figure 14: The ratio of the maximum rebound deformation and the maximum compression deformation versus impact energy.

indicates that delamination will occur for the impact energy of $150 \mathrm{~J}$.

3.3. Conversion of Energy. The conversion of the energy in the system that consists of the puncher and the layered model is investigated. Right before the puncher touches the track slab, the energy of the whole system equals the kinetic energy of the puncher. After the puncher impacts the track slab, a portion of the kinetic energy converse into the internal energy of the layered track structure. There will also be a portion of the energy that is absorbed due to the interfacial damage and delamination.

Figure 15 shows the conversion between the kinetic energy, internal energy, and absorbed energy for the impact energy of $250 \mathrm{~J}$. As seen from Figure 15, the kinetic energy and the internal energy have an inverse trend of variation. With greater kinetic energy comes smaller internal energy. The total energy of the whole system attenuates as time grows, whereas the absorbed energy increases. To interpret the whole progress of the impact, five moments are selected and plotted in Figure 15 to divide the whole impact process into several stages. Line I represents the moment when the puncher touches the track slab; Line II represents the moment when the track slab reaches the maximum compression deformation; Line III represents the moment when the track slab rebounds back to the equilibrium position; Line IV represents the moment when the track slab reaches the maximum tensile deformation; Line $\mathrm{V}$ represents the moment when the track slab moves back to the equilibrium position from the maximum tensile deformation. As seen from Figure 15, the internal energy rapidly increases to the maxima in the stage between moment I and II and then decreases to the trough in the stage between moment II and III. Before moment III, the absorbed energy slightly increases due to the small area and the low amplitude of the interfacial shear damage. After moment III, if the rebound displacement exceeds $\delta_{n}^{0}$, the tensile damage will occur. When the rebound displacement exceeds $\delta_{n}^{f}$, delamination will initiate. The corresponding

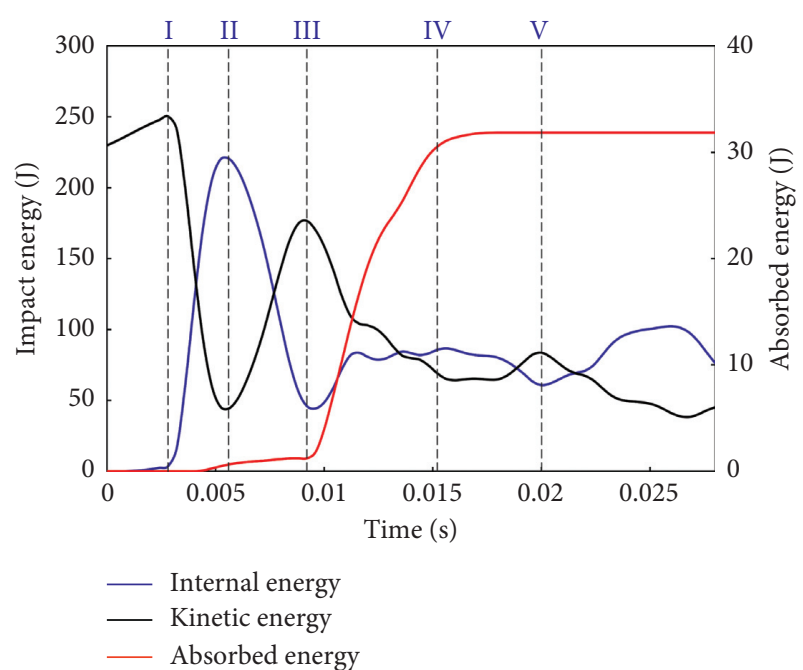

FIGURE 15: Conversion between the kinetic energy, internal energy, and absorbed energy for the impact energy of $250 \mathrm{~J}$.

absorbed energy increases significantly due to the rapid expansion of the damage and delamination.

Figure 16 shows the distribution of the interfacial damage and delamination at selected moments in terms of SDEG calculated using equation (3). Figure 16(a) represents moment II when damage occurs on the interface. The damage is mainly induced by the interfacial shear stress in the compression stage. Figure 16(b) shows moment III when the interfacial shear damage extends to the edge of the track slab. Figure 16(c) shows the moment when the tensile damage occurs in the rebound stage. Figure 16(d) illustrates moment IV when the delamination area reaches the maxima.

\subsection{Interfacial damage and Delamination for Different Impact} Energies. The area of the interfacial damage and the area of the delamination for different impact energies are shown in Figure 17. As seen from Figure 17, the two areas increase with the increase of the impact energy. For the impact energy of $300 \mathrm{~J}$, the area of the interfacial damage is approximately $8 \mathrm{~m}^{2}$, accounting for about $48.6 \%$ of the area of the track slab. For the impact energy of $300 \mathrm{~J}$, the area of the delamination is approximately $2 \mathrm{~m}^{2}$, accounting for about $12 \%$ of the area of the track slab. Figure 17 also indicates that $150 \mathrm{~J}$ is the critical impact energy for the delamination initiation. For a train running at a speed of $300 \mathrm{~km} / \mathrm{h}$, impact energy of $150 \mathrm{~J}$ can be achieved if the dynamic irregularity height of the rail is $2 \mathrm{~mm}$. Therefore, in regular maintenance, more attention should be paid to the railway line with the height of dynamic irregularity greater than $2 \mathrm{~mm}$. Figure 18 shows the relationship between the impact energy and the maximum absorbed energy, which corresponds to the value of the platform of the absorbed energy in Figure 15. Figure 18 shows an apparent increase of the absorbed energy with the increase of the impact energy. For the impact energy of $300 \mathrm{~J}$, the energy absorbed reaches about $40 \mathrm{~J}$. 


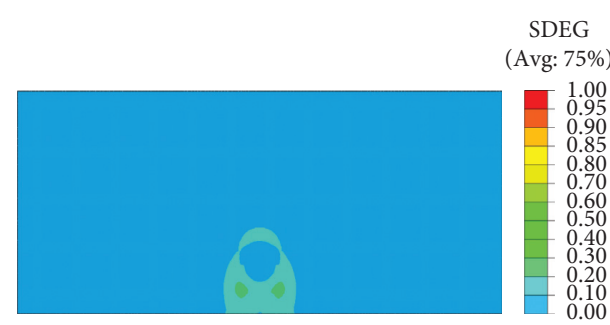

(a)

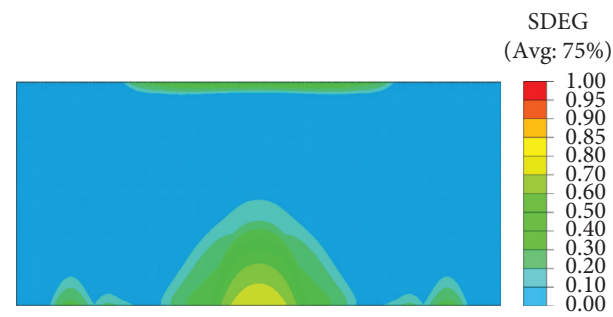

(c)

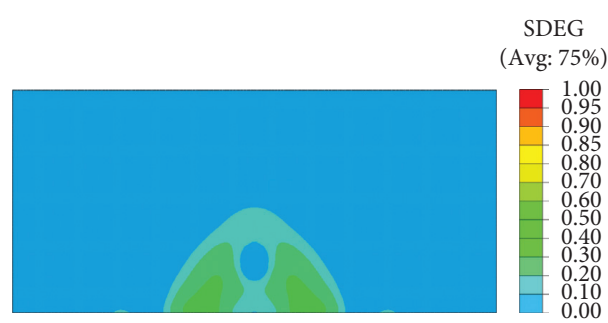

(b)

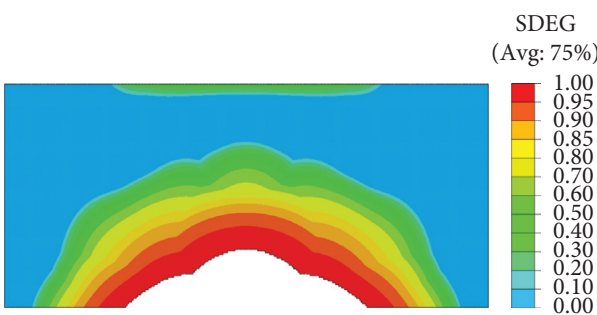

(d)

Figure 16: The evolution of the interfacial damage and delamination for selected moments. (a) Moment II. (b) Moment III. (c) The moment for the initiation of the interfacial tensile damage. (d) Moment IV.

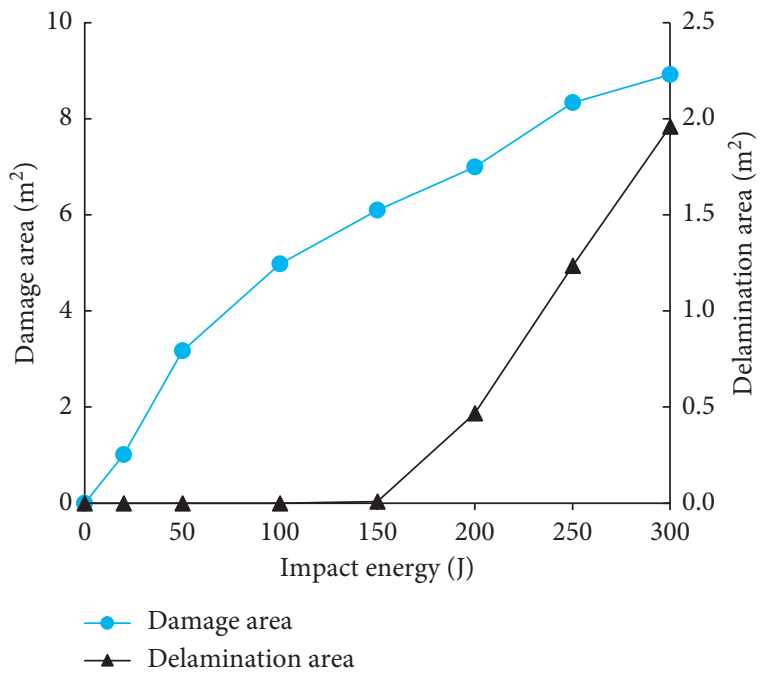

FIgURE 17: Damage area and delamination area vs. impact energy.

\subsection{Effect of Interfacial Stiffness on Interfacial Damage.} The effect of the interfacial stiffness on the interfacial damage is investigated. We first vary $E_{s}$ from $1.0 \mathrm{MPa} / \mathrm{mm}$ to $2.0 \mathrm{MPa} / \mathrm{mm}$ for the fixed $E_{n}$ of $0.7 \mathrm{MPa} / \mathrm{mm}$ and $E_{t}$ of $0.7 \mathrm{MPa} / \mathrm{mm}$ under the impact energy of $300 \mathrm{~J}$. Figure 19 shows the distribution of the interfacial damage for $E_{s}$ of $1.0 \mathrm{MPa} / \mathrm{mm}$ and $2.0 \mathrm{MPa} / \mathrm{mm}$. In Figure 19, the upper and bottom two panels indicate the distribution of the interfacial damage when the maximum vertical deformation is achieved in the compression and rebound stages, respectively. As seen from Figure 19, in the compression stage, the greater $E_{s}$ leads to the larger area of the interfacial damage. The damage is asymmetric due to the boundary effect along the transverse direction. The

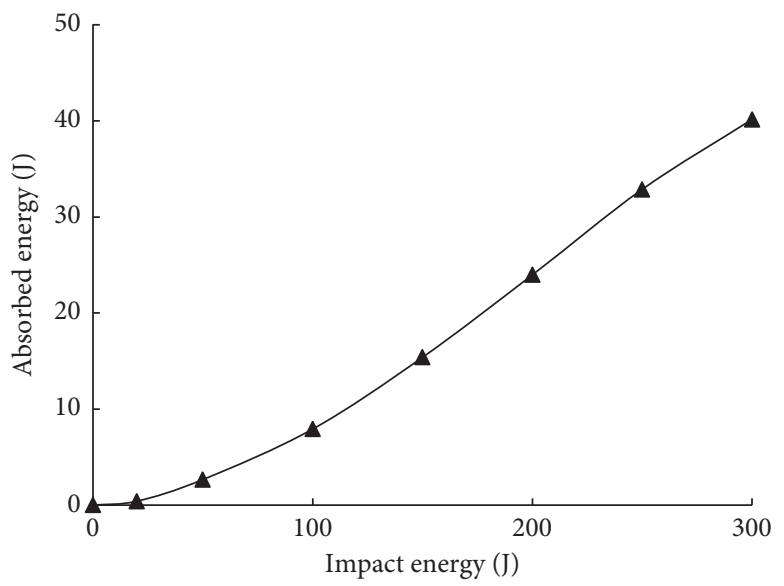

FIGURE 18: The relationship of the absorbed energy and the impact energy.

effect of $E_{s}$ on the delamination area (the blank area in the figure) is slight.

We then vary $E_{t}$ from $1.0 \mathrm{MPa} / \mathrm{mm}$ to $3.0 \mathrm{MPa} / \mathrm{mm}$ for the fixed $E_{n}$ of $0.7 \mathrm{MPa} / \mathrm{mm}$ and $E_{s}$ of $0.7 \mathrm{MPa} / \mathrm{mm}$ under the impact energy of $300 \mathrm{~J}$. Figure 20 shows the distribution of the interfacial damage for the $E_{t}$ of $1.0 \mathrm{MPa} / \mathrm{mm}, 1.5 \mathrm{MPa} /$ $\mathrm{mm}$, and $3.0 \mathrm{MPa} / \mathrm{mm}$, respectively. As seen from Figure 20, the damage is symmetrically distributed along the longitudinal direction of the track slab. The greater $E_{t}$ leads to the larger area of interfacial damage in the compression stage. The effect of $E_{t}$ on the delamination area is slight.

Figure 21 shows the variation of the maximum area of delamination with the tangential stiffness for various normal stiffness under the impact energy of $300 \mathrm{~J}$. As seen from Figure 21, the maximum area of delamination is not sensitive to the tangential stiffness when the normal stiffness is larger 

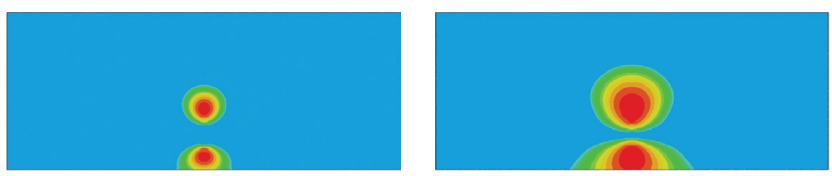

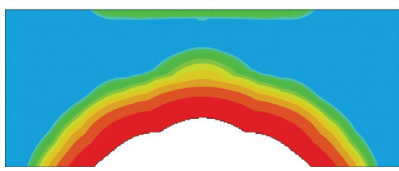

(a)

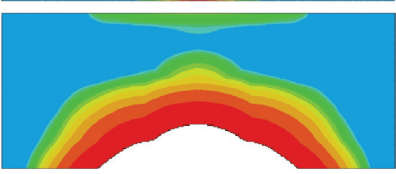

(b)

Figure 19: Distribution of the interfacial damage for the moment when the maximum vertical deformation is achieved for different $E_{s}$. The upper and bottom two panels are for the compression stage and the rebound stage, respectively. (a) $E_{s}=1.0 \mathrm{MPa} / \mathrm{mm}$. (b) $E_{s}=2.0 \mathrm{MPa} / \mathrm{mm}$.
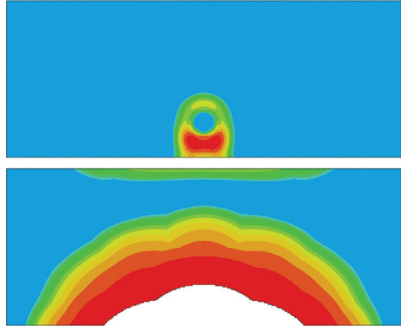

(a)
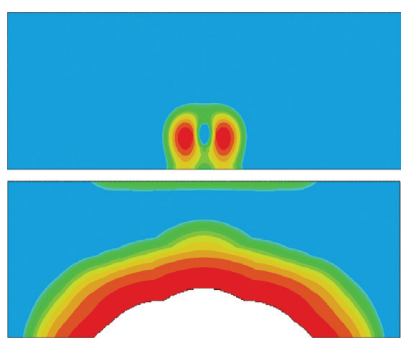

(b)
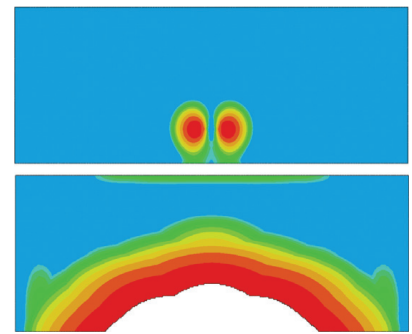

(c)

Figure 20: Distribution of the interfacial damage for the moment when the maximum vertical deformation is achieved for different $E_{t}$. The upper and bottom two panels are for the compression stage and the rebound stage, respectively. (a) $E_{t}=1.0 \mathrm{MPa} / \mathrm{mm}$. (b) $E_{t}=1.5 \mathrm{MPa} / \mathrm{mm}$. (c) $E_{t}=3.0 \mathrm{MPa} / \mathrm{mm}$.

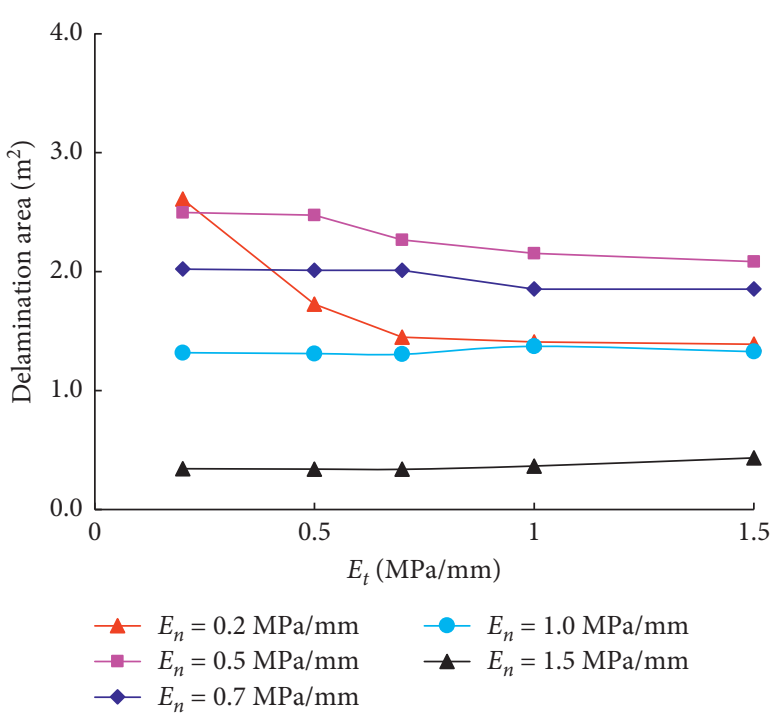

Figure 21: The delamination area versus $E_{\mathrm{t}}$ for various $E_{\mathrm{n}}$ under the impact energy of $300 \mathrm{~J}$.

than $0.5 \mathrm{MPa} / \mathrm{mm}$. The area of delamination becomes the largest when both the normal stiffness and tangential stiffness are the smallest $(0.2 \mathrm{MPa} / \mathrm{mm})$. As the tangential stiffness increases from $0.2 \mathrm{MPa} / \mathrm{mm}$ to $0.7 \mathrm{MPa} / \mathrm{mm}$, the bond behavior of the interface enhances, and thus, the area of delamination reduces rapidly. Figure 22 compares the relationship between the maximum area of delamination and $E_{t}$ for the impact energies of $200 \mathrm{~J}, 250 \mathrm{~J}$, and $300 \mathrm{~J}$,

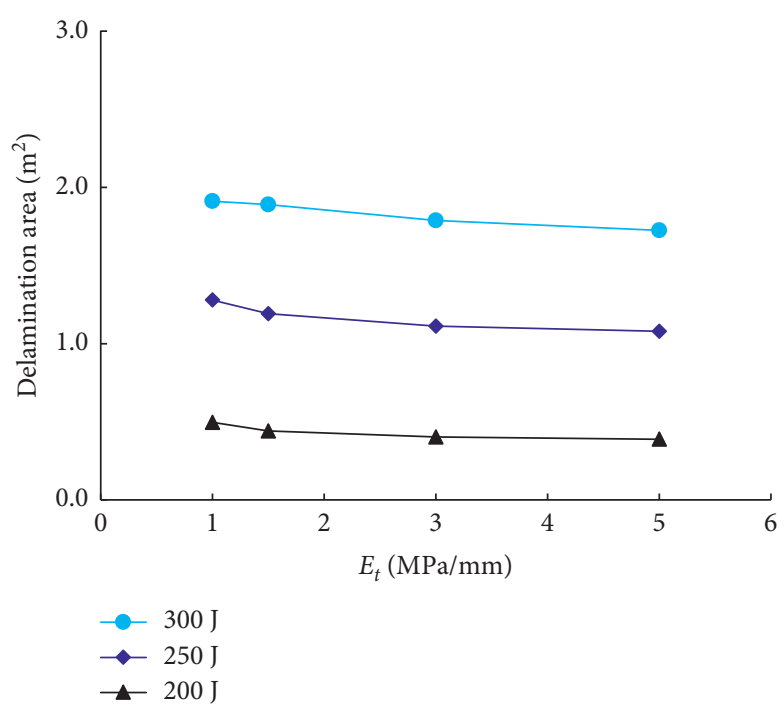

FIgURE 22: The delamination area versus $E_{t}$ for various impact energies.

respectively. Figure 22 shows that, for given impact energy, the maximum area of delamination is not sensitive to the longitudinal tangential stiffness.

Figure 23 shows the distribution of the interfacial damage when the maximum compression deformation is achieved in the compression stage and the distribution of the delamination when the maximum tensile deformation is achieved in the rebound stage for selected $E_{n}$ under the impact energy of $300 \mathrm{~J}$. As seen from Figure 23, the distribution of the interfacial 

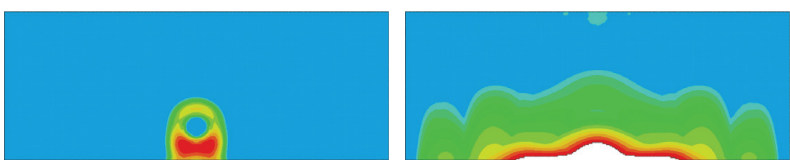

(a)
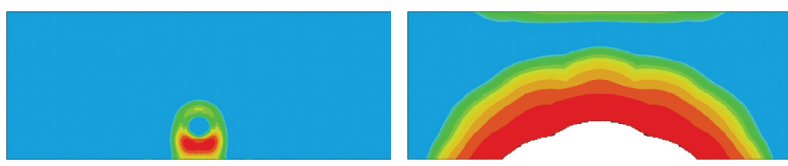

(c)

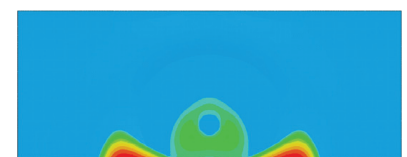

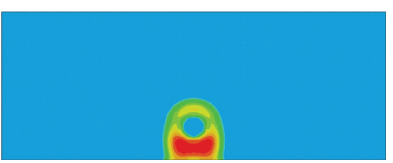

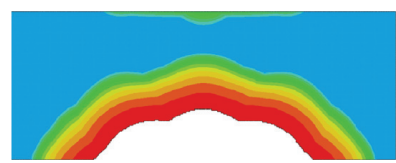

(b)
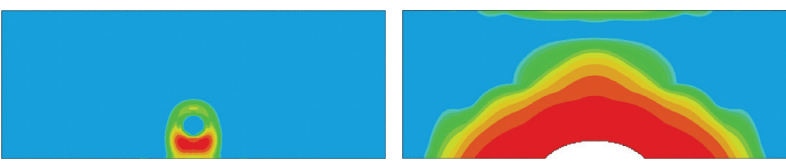

(d)

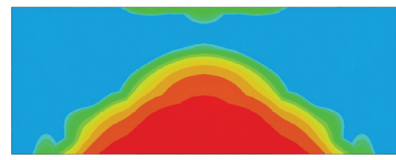

(e)

FiguRE 23: Distribution of the interfacial damage when the maximum vertical deformation is achieved for different $E_{n}$. The left and right five panels are for the compression stage and the rebound stage, respectively. (a) $E_{n}=0.2 \mathrm{MPa} / \mathrm{mm}$. (b) $E_{n}=0.5 \mathrm{MPa} / \mathrm{mm}$. (c) $E_{n}=1.0 \mathrm{MPa} / \mathrm{mm}$. (d) $E_{n}=1.5 \mathrm{MPa} / \mathrm{mm}$. (e) $E_{n}=2.0 \mathrm{MPa} / \mathrm{mm}$.

damage in the compression stage is almost the same for all cases except for $E_{n}$ of $2.0 \mathrm{MPa} / \mathrm{mm}$, which indicates a very slight effect of the normal stiffness on the interfacial damage in the compression stage. As the normal stiffness increases, the maximum area of delamination shows a trend of increasing first and then decreasing. This trend is more obvious in Figure 24 which shows the variation of the maximum area of delamination with the normal stiffness for various tangential stiffnesses under the impact energy of $300 \mathrm{~J}$.

As seen from Figure 24, for almost all tangential stiffnesses, the delamination area achieves the maxima when the normal stiffness is $0.5 \mathrm{MPa} / \mathrm{mm}$. Only when the tangential stiffness is $0.2 \mathrm{MPa} / \mathrm{mm}$, the maximum area of delamination will be achieved at a smaller normal stiffness. Figure 25 compares the maximum area of delamination versus the normal stiffness for the impact energies of $200 \mathrm{~J}, 250 \mathrm{~J}$, and $300 \mathrm{~J}$, respectively. Figure 25 indicates that, for given impact energy, the delamination area achieves the maxima when the normal stiffness is $0.5 \mathrm{MPa} / \mathrm{mm}$.

Figures 26 and 27 show the maximum compression and rebound deformation of the selected side of the track slab for various normal stiffnesses under the impact energy of $300 \mathrm{~J}$. In the compression stage, the interface of the track structure follows the continuity and uniformity assumptions of the laminated plate theory. The greater the normal stiffness of the interface, the stronger the ability of deformation compatibility, and hence the smaller the maximum vertical deformation, as shown in Figure 26. In the rebound stage, it can also be observed that a greater normal stiffness gives a smaller maximum vertical deformation except for $E_{n}$ of $0.2 \mathrm{MPa} / \mathrm{mm}$. The unexpected small vertical deformation for the normal stiffness of $0.2 \mathrm{MPa} / \mathrm{mm}$ may be explained in terms of the energy since the continuity and uniformity

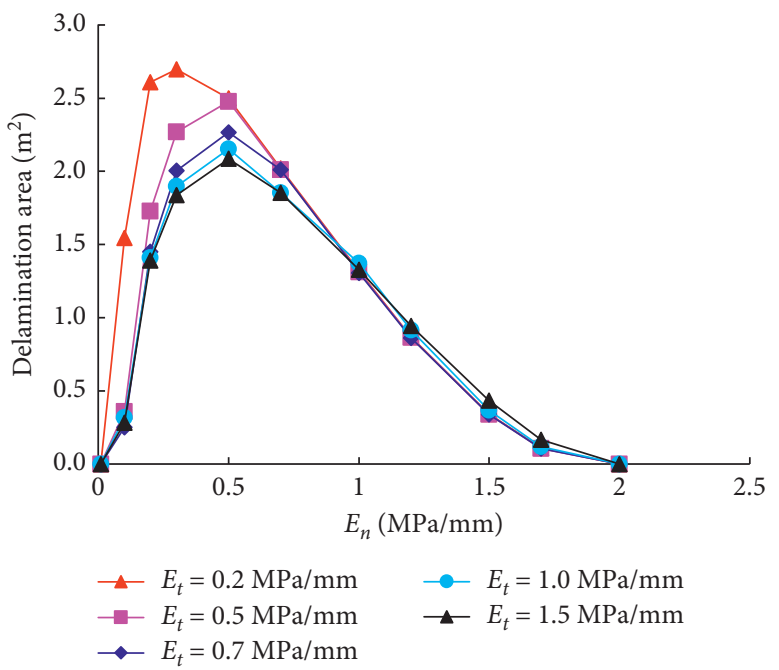

Figure 24: The delamination area versus $E_{n}$ for selected $E_{t}$ under the impact energy of $300 \mathrm{~J}$.

assumptions are not valid due to the existence of the delamination. As seen from Figure 26, the normal stiffness of $0.2 \mathrm{MPa} / \mathrm{mm}$ leads to a remarkably larger vertical deformation than other normal stiffness. This larger deformation will cause a larger consumption of the impact energy, which hence leads to a smaller energy left for the puncher to rebound. This is the reason why $0.2 \mathrm{MPa} / \mathrm{mm}$ gives a lower rebound deformation and a smaller area of delamination than $0.5 \mathrm{MPa} / \mathrm{mm}$. However, it cannot be concluded that $0.2 \mathrm{MPa} / \mathrm{mm}$ is more recommended than $0.5 \mathrm{MPa} / \mathrm{mm}$ because the larger compression deformation for $0.2 \mathrm{MPa} /$ $\mathrm{mm}$ will be a big challenge to the track irregularity limit. 


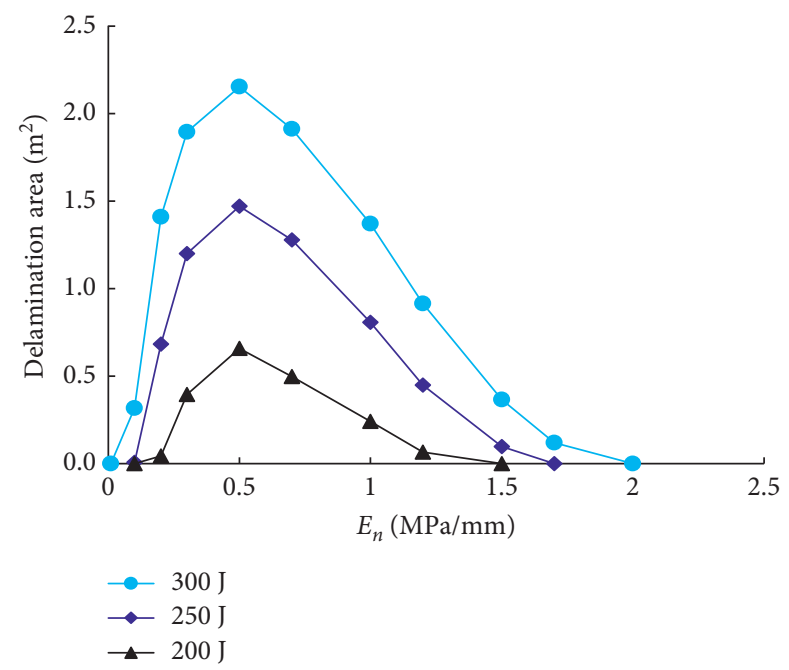

Figure 25: The delamination area versus $E_{n}$ for selected impact energies.

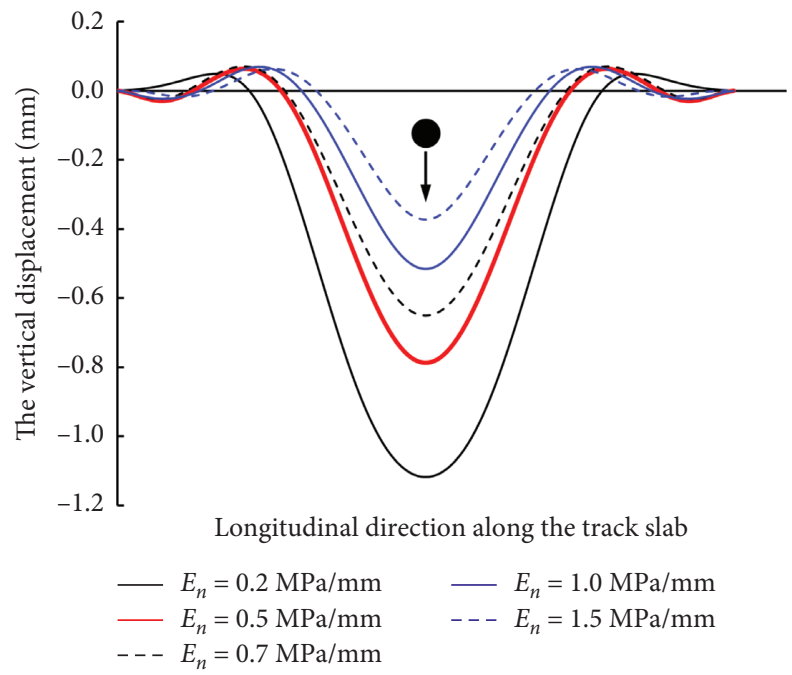

FiguRE 26: Maximum compression deformation of the selected side for various $E_{n}$.

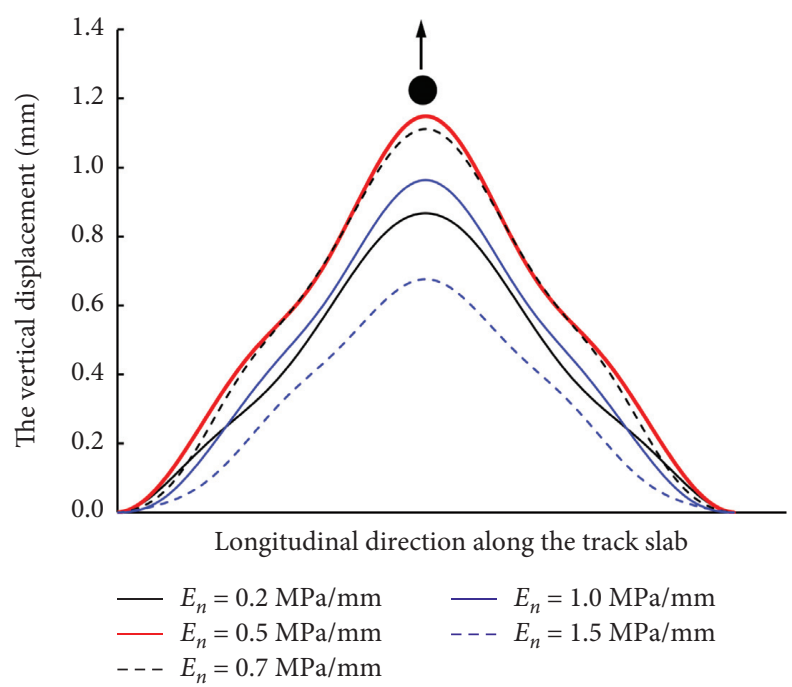

FIgURE 27: Maximum rebound deformation of the selected side for various $E_{n}$. 
Therefore, it is reasonable to take $0.5 \mathrm{MPa} / \mathrm{mm}$ as the lower bound of the normal stiffness to meet the requirement of both the delamination control and track irregularity limit.

\section{Conclusions}

The evolution of the interfacial damage and delamination of CRTS II SBTS under the vertical wheel impact are simulated. Based on the simulation, the conversion of the energy during the entire impact process, the variation of the impact force, the vertical deformation of the track slab, the distribution of the interfacial damage, and the distribution of the delamination for different impact energies are analyzed. The effects of the normal and tangential stiffness on interfacial damage and delamination are discussed.

The main conclusions include

(1) The maximum contact force between the puncher and the track slab varies linearly with the impact energy, whereas the contact time is not sensitive to the level of the impact energy. The ratio of the rebound deformation over compression deformation also increases as the impact energy increases. The impact energy of $20 \mathrm{~J}$ and $150 \mathrm{~J}$ corresponds to the energy for the interfacial damage initiation and the delamination initiation, respectively. Therefore, for a train running at a speed of $300 \mathrm{~km} / \mathrm{h}$, the dynamic irregularity height of $2 \mathrm{~mm}$ that leads to the impact energy of $150 \mathrm{~J}$ should be more concerned.

(2) During the entire impact process, the kinetic energy and the internal energy have an inverse trend of variation. With greater kinetic energy comes smaller internal energy. The absorbed energy increases rapidly along with the expansion of the damage and delamination. The greater the impact energy, the larger the energy absorbed.

(3) The interfacial damage in the compression stage is more correlated to the tangential stiffness than the normal stiffness, whereas the maximum area of delamination is controlled by the normal stiffness. The greater the longitudinal tangential stiffness, the greater the area and amplitude of the interfacial damage in the compression stage. As the normal stiffness increases, the maximum area of delamination shows a trend of increasing first and then decreasing. There is always a critical normal stiffness that gives the largest area of delamination. This critical value depends on the geometrical and material properties of the track structure. It is suggested to find this critical normal stiffness for both controlling the delamination and preventing an exceedance of the track irregularity limit.

This is the first trial to investigate the interfacial damage and delamination by considering the wheel-rail contact as a vertical impact. The relationship between the impact response and the impact energy is consistent with that of the research for composite material [25]. It is a preliminary attempt to interpret the generation of delamination of the track structure from the energy point of view. This paper concentrates on a single time of impact to exhibit the energy conversion and the evolution of the interfacial damage and delamination. Future analysis could be conducted on the cumulative damage of the interface under the cyclic wheel impact. Field test would be a powerful tool to validate the simulated result in this paper. However, due to the limits of the experimental facilities and cost, there is still a lack of the full-scale test regarding the interfacial damage of CRTS II SBTS caused by the vertical wheel impact. There once was a wheel-drop test of CRTS II SBTS, in which, however, only the acceleration of the track slab was recorded [26]. The development of the interfacial damage was not observed due to technical difficulty. Future work could also be conducted on the full-scale or scale model test of CRTS II SBTS under wheel impact so that the simulated result in this study could be validated.

\section{Data Availability}

The data used to support the findings of this study are available from the corresponding author upon request.

\section{Conflicts of Interest}

The authors declare no potential conflicts of interest with respect to the research, authorship, and/or publication of this article.

\section{Acknowledgments}

This research was financially supported by the National Natural Science Foundation of China (Grants nos. 51708459 and 51878578), the Project of Science and Technology Research Development of China Railway Co., Ltd. (Grant no. K2020G007), and the Open Foundation of UndergraduateOriented Engineering Practice Project of Key Laboratory of Southwest Jiaotong University (ZD2020010035).

\section{References}

[1] G. T. Zhao, L. Gao, L. Zhao, and Y. Zhong, "Analysis of dynamic effect of gap under CRTS II track slab and operation evaluation," Journal of the China Railway Society, vol. 39, no. 1, pp. 1-10, 2017.

[2] X. Cai, B. Luo, Y. Zhong, Y. Zhang, and B. Hou, "Arching mechanism of the slab joints in CRTSII slab track under high temperature conditions," Engineering Failure Analysis, vol. 98, pp. 95-108, 2019.

[3] China Railway Publishing House, Maintenance Rules for Ballastless Track of High Speed Railway (Trial), China Railway Publishing House, Beijing, China, 2012.

[4] Y. Liu and G. Zhao, "Analysis of early gap between layers of CRTS II slab ballastless track structure," China Railway Science, vol. 34, no. 4, pp. 1-7, 2013.

[5] Y. Li, J. Chen, J. Wang, X. Shi, and L. Chen, "Study on the interface damage of CRTS II slab track under temperature load," Structures, vol. 26, pp. 224-236, 2020.

[6] G. Zhao and Y. Liu, "Mechanism analysis of delamination of CRTSII slab ballastless track structure," Journal of the China Railway Society, vol. 42, no. 7, pp. 117-126, 2020. 
[7] S. Zhu, J. Luo, M. Wang, and C. Cai, "Mechanical characteristic variation of ballastless track in high-speed railway: effect of train-track interaction and environment loads," Railway Engineering Science, vol. 28, no. 4, pp. 408-423, 2020.

[8] S. Zhu and C. Cai, "Interface damage and its effect on vibrations of slab track under temperature and vehicle dynamic loads," International Journal of Non-linear Mechanics, vol. 58, pp. 222-232, 2014.

[9] X. Lei, S. Wu, and B. Zhang, "Dynamic analysis of the high speed train and slab track nonlinear coupling system with the cross iteration algorithm," Journal of Nonlinear Dynamics, vol. 2016, Article ID 8356160, 17 pages, 2016.

[10] P. Robinson and G. Davies, "Impactor mass and specimen geometry effects in low velocity impact of laminated composites," International Journal of Impact Engineering, vol. 12, no. 2, pp. 189-207, 1992.

[11] F. Yang and W. Cantwell, "Impact damage initiation in composite materials," Composites Science and Technology, vol. 70, no. 2, pp. 336-342, 2010.

[12] Z. Wu, L. Zhang, Z. Ying, J. Ke, and X. Hu, "Low-velocity impact performance of hybrid 3D carbon/glass woven orthogonal composite: experiment and simulation," Composites Part B, vol. 196, Article ID 108098, 2020.

[13] J. Zhou, B. Liao, Y. Shi, L. Ning, Y. Zuo, and L. Jia, "Experimental investigation of the double impact position effect on the mechanical behavior of low-velocity impact in CFRP laminates," Composites Part B, vol. 193, Article ID 108020, 2020.

[14] Y. Tai, T. Chu, H. Hu, and J. Wu, "Dynamic response of a reinforced concrete slab subjected to air blast load," Theoretical and Applied Fracture Mechanics, vol. 56, no. 3, pp. 140-147, 2011.

[15] Z. Leng, W. Lu, M. Chen et al., "Explosion energy transmission under side initiation and its effect on rock fragmentation," International Journal of Rock Mechanics and Mining Sciences, vol. 86, pp. 245-254, 2016.

[16] S. Kaewunruen, C. Ngamkhanong, and C. Lim, "Damage and failure modes of railway prestressed concrete sleepers with holes/web openings subject to impact loading conditions," Engineering Structures, vol. 176, pp. 840-848, 2018.

[17] J. Wu, Y. Zhou, R. Zhang, C. Liu, and Z. Zhang, "Numerical simulation of reinforced concrete slab subjected to blast loading and the structural damage assessment," Engineering Failure Analysis, vol. 118, Article ID 104926, 2020.

[18] T. Yilmaz, N. Kıraça, Ö. Anil et al., "Experimental investigation of impact behaviour of RC slab with different reinforcement ratios," Structural Engineering, vol. 24, no. 1, pp. 1-14, 2019.

[19] R. Talreja and C. Singh, Damage and Failure of Composite Materials, Cambridge University Press, New York, NY, USA, 2012.

[20] H. Tuo, Z. Lu, X. Ma, C. Zhang, and S. Chen, “An experimental and numerical investigation on low-velocity impact damage and compression-after-impact behavior of composite laminates," Composites Part B: Engineering, vol. 167, pp. 329-341, 2019.

[21] M. Donadon, L. Iannucci, B. Falzon, J. Hodgkinson, and S. De Almeida, "A progressive failure model for composite laminates subjected to low velocity impact damage," Computers \& Structures, vol. 86, no. 11-12, pp. 1232-1252, 2008.

[22] J. Zhou, P. Wen, and S. Wang, "Finite element analysis of a modified progressive damage model for composite laminates under low-velocity impact," Composite Structures, vol. 225, Article ID 111113, 2019.
[23] A. Riccio, A. De Luca, G. Di Felice, and F. Caputo, "Modelling the simulation of impact induced damage onset and evolution in composites," Composites Part B: Engineering, vol. 66, pp. 340-347, 2014.

[24] L. Luo, G. Zhang, W. Wu et al., Control of Track Smoothness of Wheel-Rail System, China Railway Publishing House, Beijing, China, 2006.

[25] T. Pärnänen, M. Kanerva, E. Sarlin, and O. Saarela, "Debonding and impact damage in stainless steel fibre metal laminates prior to metal fracture," Composite Structures, vol. 119, pp. 777-786, 2015.

[26] W. Zhai, K. Wang, Z. Chen, S. Zhu, C. Cai, and G. Liu, "Fullscale multi-functional test platform for investigating mechanical performance of track-subgrade systems of highspeed railways," Railway Engineering Science, vol. 28, no. 3, pp. 213-231, 2020. 